\title{
Hydrological Evaluation of Satellite and Reanalysis-based Rainfall Estimates Over the Upper Tekeze Basin, Ethiopia
}

\author{
Kidane Reda ${ }^{1}$, Xingcai Liu ${ }^{1}$, Gebremedhin Haile², Siao Sun ${ }^{3}$, and Qiuhong Tang ${ }^{1}$ \\ ${ }^{1}$ Key Laboratory of Water Cycle \& Related Land Surface Processes Chinese Academy of \\ Sciences \\ ${ }^{2}$ Tigray Agricultural Research Institute, Mekelle, Tigray, Ethiopia \\ ${ }^{3}$ Key Laboratory of Regional Sustainable Development Modeling, Institute of Geographic \\ Sciences and Natural Resources Research, Chinese Academy of Sciences, Beijing, China
}

March 5, 2021

\begin{abstract}
Spatial rainfall data is an essential input to physically based, parametrically distributed hydrological models, and a main contributor to hydrological model uncertainty. Two important issues should be addressed before use of satellite and reanalysis rainfall product at basin level: 1) how useful are these rainfall estimates as forcing data for regional hydrological modeling? 2) which should be preferred for hydrological modelling at high flow and low flow seasons? To this end, rainfall estimates from a satellite-based product, CHIRPSv8, and reanalysis data, EWEMBI, were used as input to SWAT model, and mode performances were evaluated against streamflow measured at three gauge stations in the Upper Tekeze River basin, northern Ethiopia for the period of 2006-2015. Results showed that (I) the daily rainfall from both CHIRPSv8 and EWEMBI are close to the rain gauge data, with relative errors $2.12 \%$ and $3.85 \%$, respectively; (II) the monthly streamflow simulated by the SWAT model driven by the CHIRPSv8 and EWEMBI had a Kling-Gupta Efficiency value of 0.6-0.79 and 0.58-0.64, respectively; (III) the SWAT model calibrated with the CHIRPSv8 and EWEMBI rainfall estimates has shown an improvement in hydrological performance compared with that calibrated with interpolated ground observations; (IV) the hydrological performance during high flow seasons is superior to low flow seasons for both CHIRPSv8 and EWEMBI, thus promoting the use of the products for applications focusing on the high flow conditions. In particular, CHIRPSv8 showed relatively better hydrologic performance than EWEMBI. This study provides insight on the usefulness of the gridded rainfall products for hydrological modeling and under which conditions they can be used to generate a plausible level of adequacy and reliability over the Upper Tekeze River basin.
\end{abstract}

\section{Hosted file}

Main document.pdf available at https://authorea.com/users/399736/articles/512180hydrological-evaluation-of-satellite-and-reanalysis-based-rainfall-estimates-over-theupper-tekeze-basin-ethiopia 

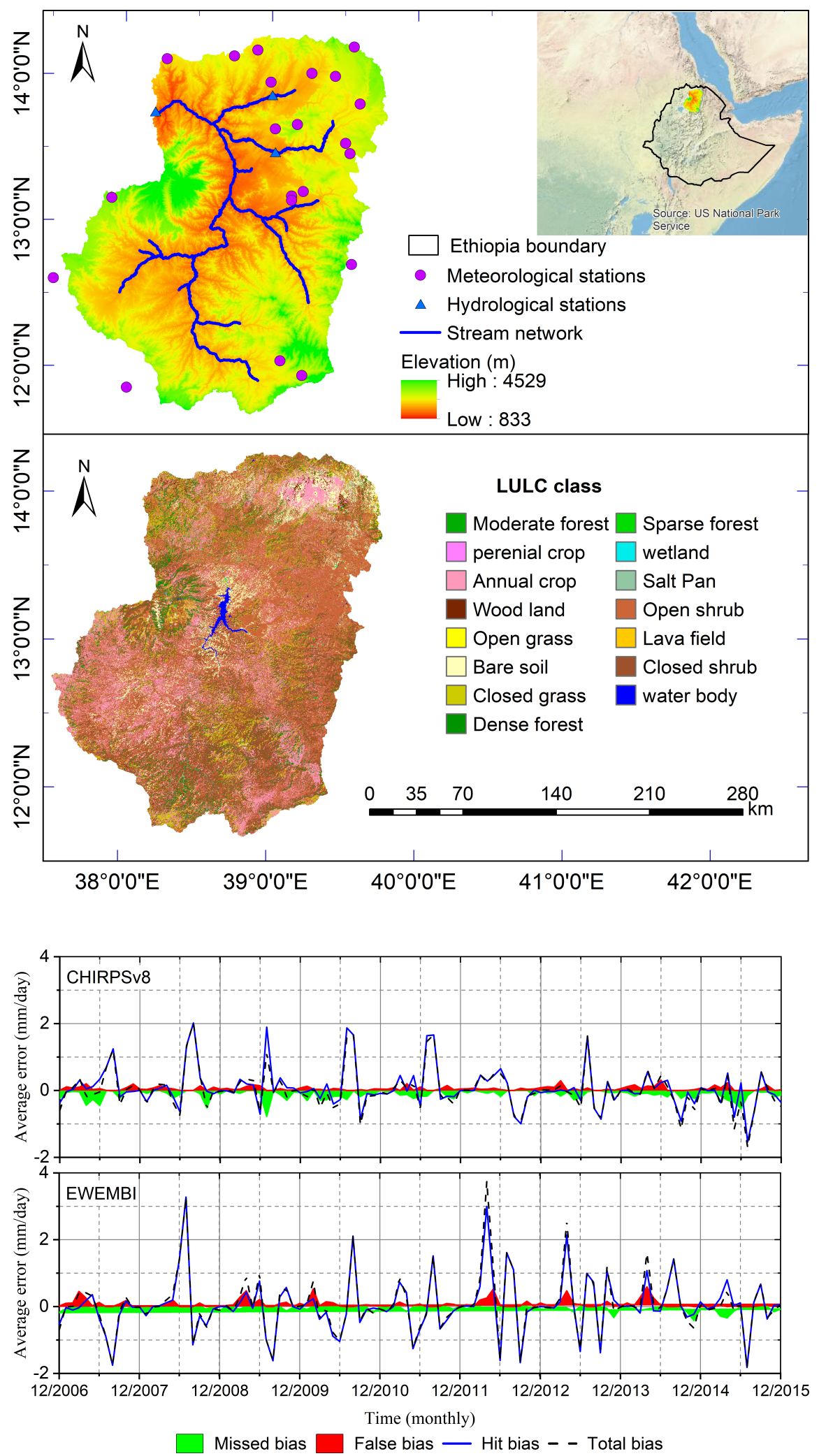

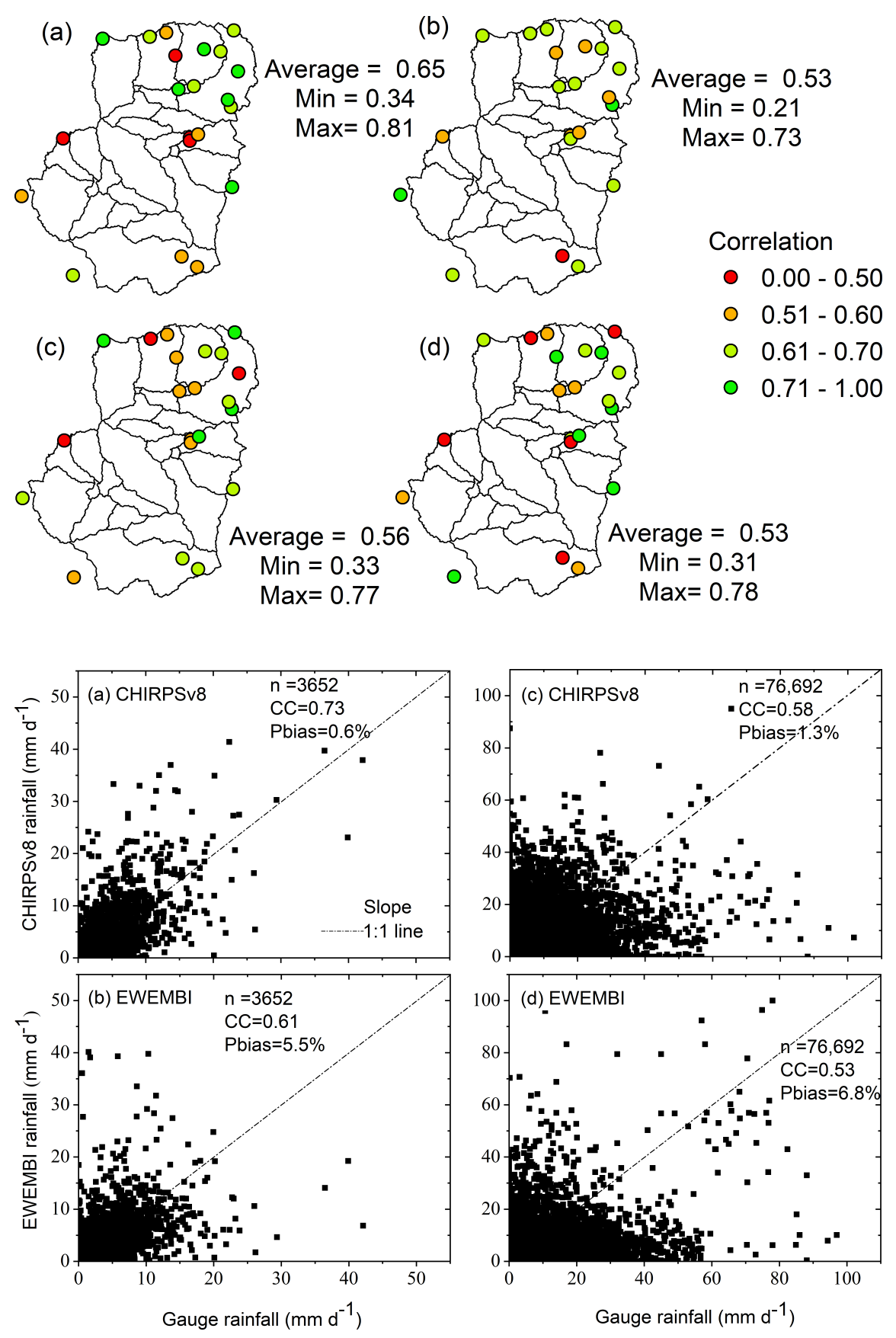

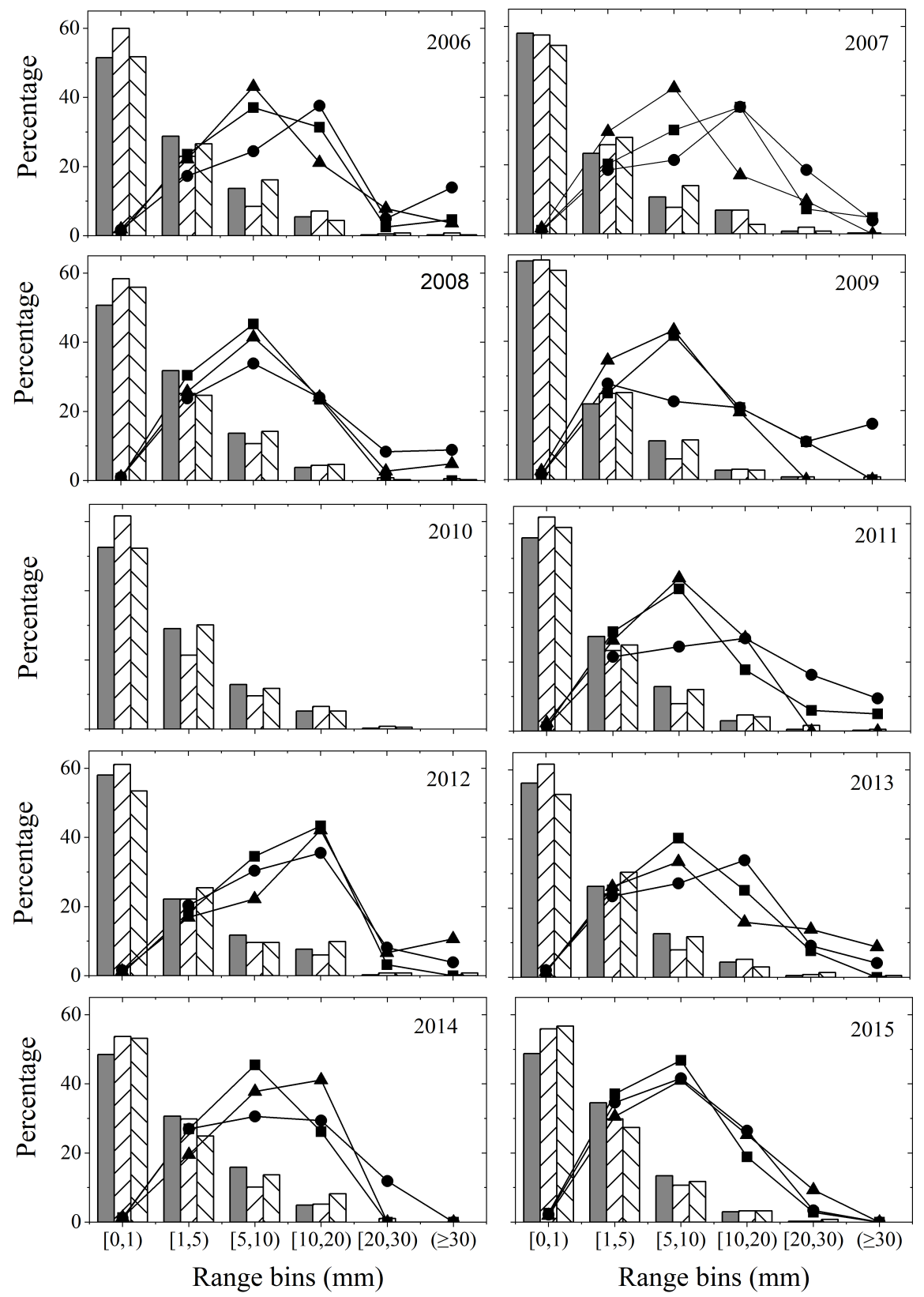

$\square$ Occurrence_Gauge $Z \triangle$ Occurrence_CHIRPS $\triangle \backslash$ Occurrence_EWEMBI

$\longrightarrow$ Contribution_Gauge $-\longrightarrow$ Contribution_CHIRPS - -Contribution_EWEMBI 

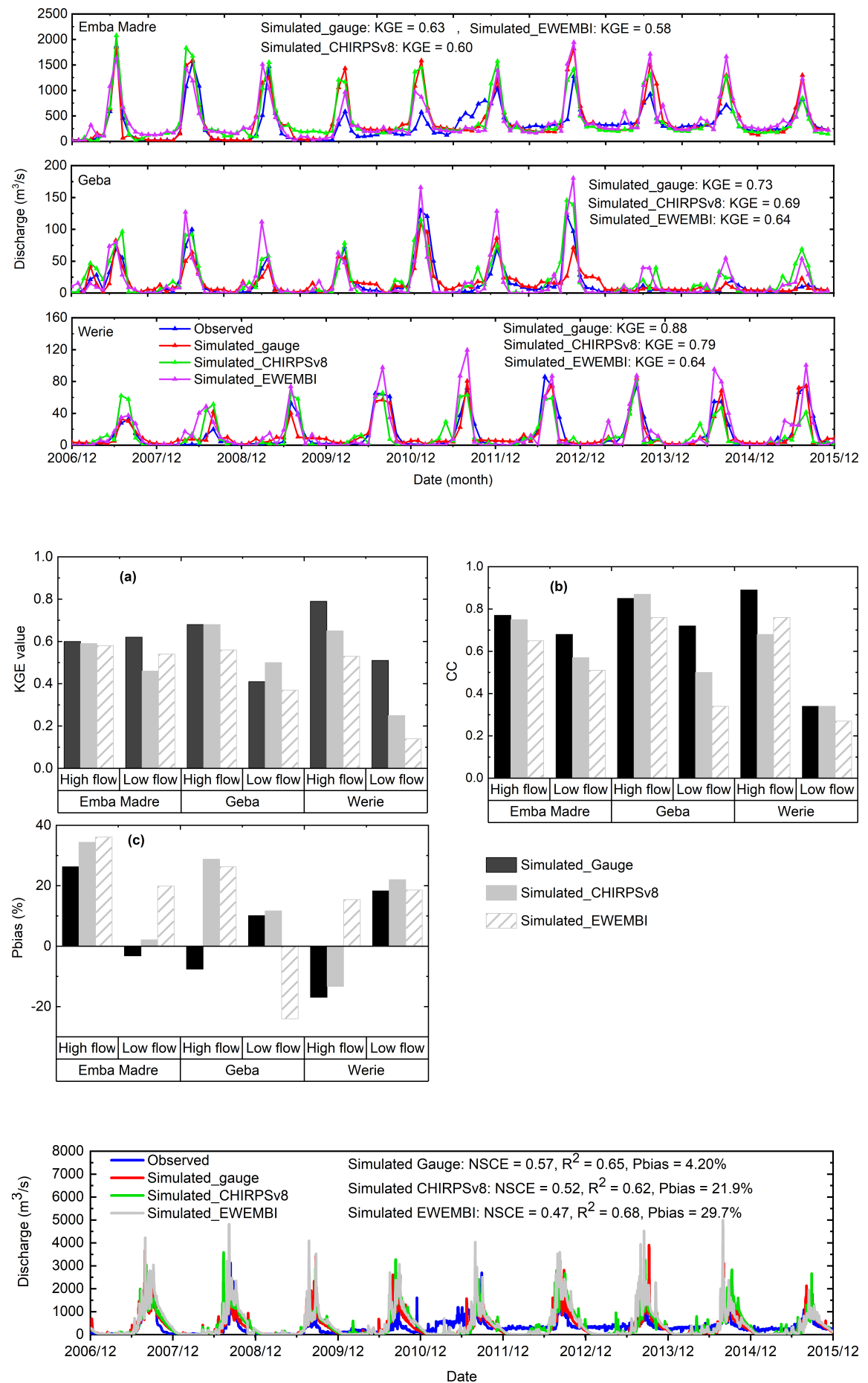


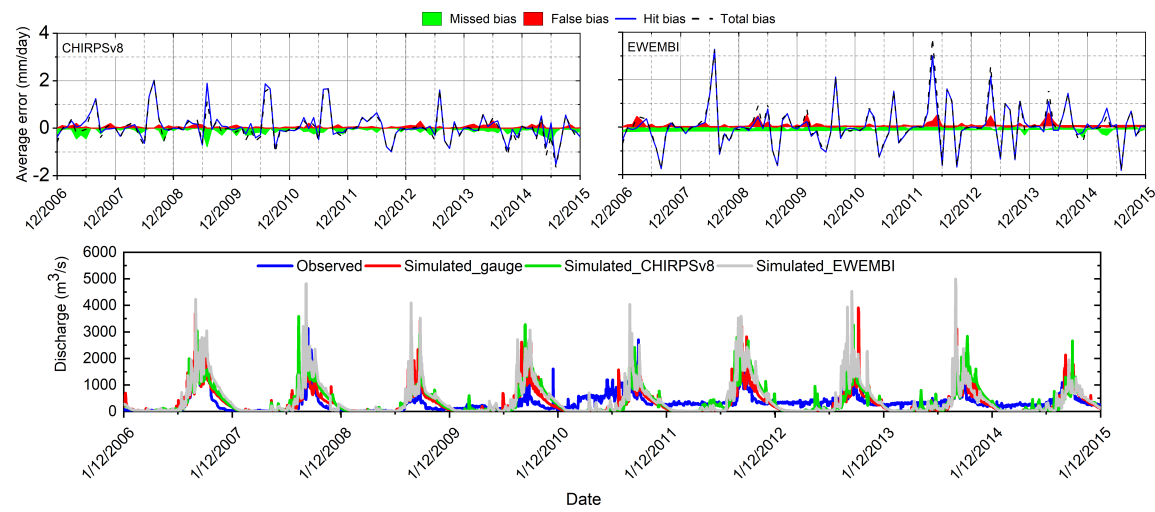

